International Journal of Medical Sciences

ISSN 1449-1907 www.medsci.org 2005 2(3):100-106

Review

(C)2005 Ivyspring International Publisher. All rights reserved

\title{
Risk and Benefit of Drug Use During Pregnancy
}

\section{Ferenc Bánhidy ${ }^{1}$, R.Brian Lowry² and Andrew E. Czeizel ${ }^{3}$}

1 Second Department of Obstetrics and Gynecology, Semmelweis University, School of Medicine, Budapest, Hungary

2 Department of Medical Genetics, University of Calgary and Alberta, Children's Hospital Calgary, Canada

3 Foundation for the Community Control of Hereditary Diseases, Budapest, Hungary

Corresponding address: Dr. Andrew E.Czeizel, 1026 Budapest, Törökvész lejtő 32, Hungary. e-mail: czeizel@interware.hu

Received: 2005.05.01; Accepted: 2005.06.03; Published: 2005.07.01

Environmental teratogenic factors (e.g. alcohol) are preventable. We focus our analysis on human teratogenic drugs which are not used frequently during pregnancy. The previous human teratogenic studies had serious methodological problems, e.g. the first trimester concept is outdated because environmental teratogens cannot induce congenital abnormalities in the first month of gestation. In addition, teratogens usually cause specific congenital abnormalities or syndromes. Finally, the importance of chemical structures, administrative routes and reasons for treatment at the evaluation of medicinal products was not considered. On the other hand, in the so-called case-control epidemiological studies in general recall bias was not limited. These biases explain that the teratogenic risk of drugs is exaggerated, while the benefit of medicine use during pregnancy is underestimated. Thus, a better balance is needed between the risk and benefit of drug treatments during pregnancy. Of course, we have to do our best to reduce the risk of teratogenic drugs as much as possible, however, it is worth stressing the preventive effect of drugs for maternal diseases (e.g. diabetes mellitus and hyperthermia) related congenital abnormalities.

K ey words: human teratogenic drugs, congenital abnormalities, critical period, recall bias, congenital abnormality, preventive effect of drugs.

\section{Introduction}

Among environmental factors, dangerous lifestyle seems to be the greatest hazard for the development of the fetus due to the common practice of consuming alcohol and smoking tobacco. Alcohol may cause fetal alcohol syndrome or at least fetal alcohol effects [1,2]. It is preventable by abstinence during pregnancy but often unavoidable because approximately $50 \%$ of pregnancies are unplanned and hence alcohol consumption occurs before a woman knows that she is pregnant. Recently the teratogenic potential of smoking has been shown in some congenital abnormalities (CAs), particularly terminal transverse type of limb deficiencies [3] and Poland sequence [4], while the gene-environmental interaction was shown in the origin of orofacial clefts [5]. The role of teratogenic effect of environmental pollutants such as methyl mercury [6] was also reported but we cannot estimate the magnitude of this problem. The primary prevention of infectious diseases by vaccination is extremely important particularly in the prevention of CAsyndromes caused by rubella and varicella viruses. Here we focus on teratogenic medication and their prevention.

\section{Human teratogenic drugs}

In Hungary $92 \%$ of pregnant women used medicinal products and the mean number of drugs and pregnancy supplements per pregnant women was 3.4 between 1980 and 1996. About $70 \%$ pregnant women were treated with drugs during pregnancy [7]. These figures are in agreement with a recent publication [8].

Experts in many countries have set up risk classification systems based on data from human and animal studies to help physicians interpret the risk associated with drugs during pregnancy. The most wellknown classification was introduced by the US Food and Drug Administration (FDA) in 1979, using the letters A, B,
C, D and $\mathrm{X}$ for five categories [9]. The definition of category A means no risk, and any risk is unlikely in category B. There is no appropriate data for drugs in category $\mathrm{C}$. The definition of category $\mathrm{D}$ is as follows: "There is positive evidence of human fetal risk, but the benefits from use in pregnant women may be acceptable despite the risk" (e.g. in a life-threatening situation). Finally, drugs with classification $X$ are "Contraindicated in women who are or may be pregnant". We do not like this classification system, because all oral contraceptives and female sex hormones (both estrogens and progestins) were classified as $X$ though we have no evidence of a teratogenic effect. It is another matter that these hormones are not indicated during pregnancy. We only found an association between very high doses of oestrogens and unimelic terminal transverse type of limb deficiency when oestrogens were used to induce illegal abortion [10]. This general teratogenic risk for limb deficiency was about $1 \%$ instead of the usual $0.05 \%$. On the other hand teratogenic and fetotoxic effects are confused though they have different time factors and consequences. Finally some other drugs were classified as $\mathrm{X}$ without any evidence for teratogenic risk (e.g. clomiphene) or with much debated findings (e.g. benzodiazepine such as flurazepam, quazepam, temazepam and triazolam). This problem is more serious in the groups of drugs with classification D because many drugs were classified without any data and were based only on the general similarity of the chemical structure. However, mild differences in the chemical structure can change the teratogenic potential, for example the teratogenic oxytetracyclines and nonteratogenic doxycycyline within the group of tetracyclines. At present the population-based Hungarian Case-Control Surveillance of Congenital Abnormalities (HCCSCA) [11] contains the largest national case-control data set in the world where the teratogenicity of about a 
hundred drugs was studied. Our findings do not confirm the teratogenic risk of benzodiazepines such as diazepam [12], chlordiazepoxide [13], nitrazepam, medazepam, tofisopam, aplrazolum and clonazepam [14]. The teratogenic effect of diazepam and some other benzodiazepines was not confirmed after self-poisoning (i.e. suicide attempt) with extremely large doses $[15,16]$. The teratogenic effect of barbitals [17], furosemide [18], aminoglycoside antibiotics [19] and povidone-iodine [20] was also not found. After the negative findings of our studies we cannot accept the risk estimation of the FDA classification system. Similar opinions were stated by other experts as well, therefore two other drug classification systems have been developed in Sweden [21] and Australia [22].

There are about 8,200 medicinal products in the Hungarian market, however, the number of chemical substances, i.e. generic drugs with human teratogenic risk is limited. Table 1 shows drugs with high and moderate teratogenic risk. Thalidomide was never marketed in Hungary, however, it is used again in some countries (e.g., Brazil) as an effective drug for leprosy and other diseases. Androgenic hormones are not indicated in the treatment of pregnant women, nevertheless some women used these drugs at the beginning of their unplanned pregnancies due to their body building activity. At present isotretinoin and etretinate are considered the most teratogenic risk used for the treatment of acne and psoriasis in Hungary, therefore an effective campaign was organized to prevent their use during pregnancy. The coumarin derivatives cause the largest clinical problem because pregnant women with a previous thrombosis history frequently need treatment. However, it is possible to change the treatment protocol and use heparin instead of coumarin derivatives in the early pregnancy because the latter drugs are teratogenic in the third and fourth months of gestation. Oxytetracyclines are also teratogenic, but these products are now not on the market. The use of oxytetracyclines was relatively frequent in Hungarian pregnant women, thus we were able to show that Tetran ${ }^{\circledR}$ induced - other than staining of deciduous teeth - a characteristic pattern of multiple CA [23].On the other hand doxycycline is not teratogenic [24]. The use of Dpenicillamine (e.g. in Wilson disease) rarely occurs and it may cause cutis laxa, not a severe CA. In addition this CA can be diminished by the parallel use of zinc. Diethylstilbestrol was also withdrawn from the market. The proportion of women treated with drugs with high and moderate teratogenic risk during the study pregnancy was $0.8 \%$ and $0.4 \%$ in the group of cases with CAs and controls without CAs in the data set of the HCCSCA, 1980-2002, respectively.

The list of drugs with low and very low teratogenic risk is longer (Table 2), though the names of drugs with fetotoxic effects, e.g., chlorothiazide, angiotensinconverting enzyme inhibitors, beta-adrenergic blocking agents, reversible goiter inducing potassium iodine, etc, are not mentioned. There is a long list of antineoplastic and anticonvulsant drugs which may be needed in pregnant women with cancer or epilepsy. At present some of them are not on the market, but most drugs in this list have a teratogenic risk between 2 and 5\%. Ergotamine and quinine derivatives were used relatively frequent. Among oestrogens and retinol (vitamin A), only high dose treatments are considered. It is worth mentioning that we had three mothers who were treated by 50,000 and one with 100,000 IU doses of vitamin A daily in the first and second months of gestation, and later they delivered newborn infants without any CAs [25]. Our finding is in agreement with the conclusion of the European Network of the Teratology Information Services, whose data set did not provide evidence for an increased risk of major CAs associated with high vitamin A intake (10,000 IU per day or more) during the organogenetic period of embryo [26].

Here we discuss three problems at the evaluation of human teratogenic risk of drugs.

\section{Low scientific quality of previous human teratogenic studies}

Unfortunately the scientific quality of most previous studies regarding risk estimation of teratogenic medications was low due to some methodological problems.

\section{Time factor: first trimester concept is outdated}

The first trimester of pregnancy was considered as the critical period of most major CAs. This supposition is unscientific and outdated [27].

At present gestation age is calculated from the first day of the last menstrual period. Thus, "pregnant women" are not pregnant in the first two weeks of their pregnancies. The third week covers the preimplantation period when the zygote goes from the external end of the Fallopian tube to the uterus. The fourth week comprises the implantation period when the blastocyst finds its site in the uterus. However, the zygotes and blastocysts have continuous mitoses producing totipotent stem cells during this period. Serious damage can cause their death, but after limited damage they have a complete recovery. These facts explain the rule of "all-or-nothing effect" or in other words the consequence of these damages have only two outcomes: complete loss of zygotes/blastocysts (which causes only some delay in the seemingly menstrual bleeding) or healthy birth.

In conclusion, human teratogenic drugs cannot induce CA in the first month of gestation because the specific activation of DNA in the stem cells and the socalled differentiation of specific cells, organs and body forms starts on the 29th day of gestation (or on the 15th postconception day). The 29th day of gestation overlaps with the first days of missing menstrual bleeding when women in general can recognize the pregnancy. Thus, it is necessary to know that before the first missed menstrual bleeding, environmental factors cannot induce CAs. The main organ-forming period lasts from the 29th day to the 70th day of gestation. The evaluation of the first trimester is therefore a serious methodological error, only the second and third months represent the critical period of most major CAs. On the other hand we know that the critical period of some CAs exceeds the end of third month, e.g., the critical period of posterior cleft palate and hypospadias covers the 12th-14th and 14th-16th weeks of gestation, while the critical period of undescended testis and patent ductus arteriosus is 7 to 9 months and 9 to 10 months, respectively. Thus, the optimal approach is to consider the specific critical period of each CA [7] separately.

\section{Specificity of teratogens}

It is not worth studying the total group of CAs because CAs have different etiological backgrounds. Therefore we have to focus our analysis on specific CAs since teratogenic drugs induce specific CAs without affecting other CAs and overall rates. Thus, we have to do 
our best to develop groups of CAs as homogeneous as possible. In addition the most teratogenic drugs cause specific CA syndromes with a characteristic pattern of component CAs. This phenomenon explains the delineation of fetal alcohol, radiation, rubella, hydantoinphenytoin, warfarin-coumarin, accutane, etc. syndromes. This rule helps us to identify the cause of specific CAsyndrome, e.g., if a case is affected with cleft lip and nail hypoplasia, we can diagnose hydantoin (phenytoin) CAsyndrome in a baby of an epileptic mother who has been treated with this drug.

Another common and serious methodological error occurs when isolated (single) and multiple (syndromic) manifestations of the seemingly same CAs are combined and evaluated together. Most isolated CAs have a complex etiology based on some polygenic predisposition which is triggered by environmental risk factors. The seemingly similar component CAs within multimalformed or syndromic cases are caused by chromosomal aberrations, gene mutations or teratogens [28]. We can easily prove the different etiopathogenetic background of isolated and multiple CAs by epidemiological methods. For example, isolated cleft lip has a left sided and male predominance while component cleft lip in syndromic cases has no side predominance and the sex ratio corresponds to the usual population figure [29]. Thus, it is an important rule to evaluate the isolated and multiple manifestations of the same CA separately.

The importance of different chemical structures, administrative routes and reasons for treatment at the teratogenic evaluation of medicinal products was not considered

In general, similar drugs were evaluated together such as penicillins, tetracyclines, cephalosporins (or sometimes as "antibiotics") and sulfonamides in the past. This approach is not correct because each drug within these groups has different chemical structure. As we mentioned previously within the group of tetracyclines, oxytetracylines [23] were teratogenic while doxycyclines [24] were not teratogenic. At the evaluation of seven orally used sulfonamides, only two showed teratogenic potential, and they induced different CAs [30].

Our studies showed the importance of interaction of different drugs. We were not able to find a clinically important teratogenic effect after the use of oral metronidazole [31] and the topical miconazole treatment resulted in an obvious negative finding [32]. Nevertheless, the vaginal use of the combination of these two drugs increased the risk for poly/syndactyly six fold [33].

Our analyses also demonstrated that it is necessary to differentiate the administrative route of drugs and their teratogenic potential. We should therefore evaluate the use of the same drugs (e.g., corticosteroids and antifungal agents) according to oral, parenteral, topical (skin, vaginal, eye and ear) and inhaled aerosol treatments separately.

Finally it is necessary to differentiate drugs and pregnancy supplements within medicinal products. Drugs are used for the treatment of maternal diseases and pregnancy complications during pregnancy while pregnancy supplements such as folic acid, other vitamins [34], iron, calcium, multivitamins, etc are given to prevent pregnancy complications and unsuccessful pregnancy outcomes particularly CAs. These opposite effects of medicinal products have to be considered when evaluating the drugs.

\section{Recall bias}

The birth of an infant with a CA is a serious traumatic event for most mothers, who therefore try to find a causal explanation such as drug use during pregnancy, something that does not occur after the birth of a healthy infant. Thus the mothers of babies affected with CAs are continually thinking of possible dangerous environmental factors and when asked about the history of their pregnancy, give a long list of supposed agents. On the other hand the mothers of healthy babies are thinking of the present and future of their babies and are likely to forget events during the pregnancy. Retrospective (i.e., after the birth) maternal self-reported information therefore is different in the groups of case and control mothers and this recall bias can mimic an increased risk of drugs in the CA-groups up to an odds ratio of 1.9 (35). Thus a higher risk of less than 1.9 should be interpreted cautiously. In addition, it is possible to reduce recall bias.

Firstly, we evaluate $25 \mathrm{CA}$-groups and we expect a higher occurrence of one or some CA-groups after the use of the given drug due to the specificity of teratogens. Recall bias may act for all CAs similarly.

Secondly, the use of the drug under study is evaluated during the critical period of CA formation, in general the second and third months of gestation. We may suppose that the teratogenic effect of the drug is shown only during this period because we expect an underreporting of exposure in both the critical and noncritical periods of CA formation in the mothers of healthy babies, i.e., in the population control group.

Thirdly, an independent and prospective source of drug exposure data, e.g., the medically recorded data in the prenatal logbook may serve as a gold standard. Our validation study, however, showed that a small group of pregnant women $(2.4 \%)$ did not use prescribed and medically recorded drugs or they shortened the duration of treatment due to the supposed teratogenic risk [36]. Another independent and prospective source of drug exposure can be found in pharmacy records [37].

Fourthly, it is worth using a patient control group including mothers of cases with other CAs. In our HCCSCA system, cases with Down syndrome are used as patient controls [11] because the cause of this numerical chromosomal aberration (trisomy 21) is not connected with the teratogenic effect of agents during pregnancy, and particularly in the critical period of most CA formation, i.e., during the second and third months of gestation.

Fifthly, "true" teratogens such as rubella virus, radiation, alcohol, hydantoin-phenytoin, warfarincoumarin, accutane, etc., cause multiple CA with a characteristic pattern of CAs. Thus multimalformed cases need a special and detailed analysis [28] because these data are not distorted by recall bias. Another group of teratogens plays a role as trigger factors in the origin of isolated CAs based on polygenic-environmental interaction, i.e. multifactorial etiology.

\section{Teratogenic risk of drugs is exaggerated.}

The exaggeration of drug teratogenicity can be explained by several factors.

1. At present the average number of children per family in Hungary is about 1.3 compared to 11 in the 19th century. In the past, the social role of females was the "reproduction" of human beings. Now they take part in the social "production" outside their homes similar to 
males but they have to fulfill their traditional role of reproduction as well. A malformed or disabled child curtails their social activity hence the emphasis on having a healthy baby.

2. The positive findings of animal investigations are frequently extrapolated for the human fetus contrary to the well-known species specificity.

3. The previous teratologic studies had several methodological weaknesses and recall bias which are summarized above and which resulted in false positive findings.

4. The editors of scientific periodicals have an aversion to publishing papers with negative results, but are happy to publish selected case reports and the positive findings of animal and human epidemiological studies. This publication bias distorts the thinking of experts as well as the general population.

5 . The false balance of risk and benefit of drug use during pregnancy is seriously augmented by the defensive policy of pharmaceutical companies and regulatory agencies which are gradually labeling most drugs with the recommendations to avoid their use during pregnancy, at least in "the first trimester".

6. This unbalanced opinion is amplified by a self defensive attitude of some doctors and is partly understandable. They may not be well informed and may exaggerate the risk by relying on manufacturers drug pamphlets. They may also be thinking about possible law suits and are therefore over cautious forgetting that the chance of any pregnancy ending with a baby who has a major CA is approximately $3 \%$.

The exaggeration of teratogenic risk of medicinal products causes several hazards.

First, many pregnant women do not get the necessary drug treatment and it results in serious consequences both for the mothers and their fetuses. If influenza [38] and other acute infectious diseases of respiratory system [39] with high fever in early pregnancy are not treated by appropriate methods including drugs, therefore the teratogenic effect of hyperthermia can induce hyperthermic embryopathy (Table 3), among others, neural-tube defects. In Hungary, about $40 \%$ of pregnant women have some sexually transmitted infections and/or diseases in their genital organs [40]. Most medical doctors do not dare to treat them, therefore the ascending infections are followed by preterm birth and serious intrauterine infection of the fetus. Our study showed that the fetuses of inappropriately or untreated asthmatic pregnant women have a higher risk for intrauterine growth retardation [41].

Second, many planned and wanted pregnancies are terminated due to the anxiety and fear created by the notion that nearly all drugs cause CAs [42]. Recently the number of induced abortions before the 12th week of gestation is about 60,000 per year in Hungary and about 3,000 are terminated due to a medical indication connected to drug use during pregnancy. However, our analysis showed that the great majority of these pregnancy terminations had unfounded medical indications [43].

Third, pregnant women using necessary drug treatments may suffer permanent psychological stress and may be seriously depressed until the end of the pregnancy [44].

Fortunately the scientifically proved human teratogenic drugs are not used frequently in pregnant women (Table 1 and 2). The total proportion of CAs induced by drugs is less than $1 \%$ in the database of the HCCSCA, if we calculate 65.27 per 1,000 total rate of CAs in Hungary [45].

\section{Benefit of medicine use during pregnancy is underestimated}

Maternal drug use during pregnancy may pose a teratogenic risk for the embryo. However, the recommendation to avoid all drugs during early pregnancy [42] is unrealistic and may be dangerous. About $8 \%$ of pregnant women need permanent drug treatment due to their chronic diseases such as epilepsy, diabetes mellitus, bronchial asthma, hypertension, thyroid disorders, migraine, and severe depression [40]. More pregnant women require transient drug treatment because of influenza, acute infectious diseases of respiratory system and urogenital organs, the latter mainly due to sexually transmitted infections. In addition, headache, nervousness, constipation and other common complaints may also need drug treatments. Finally there are many pregnancy complications such as nausea and vomiting, threatened abortion, preterm delivery, toxemia and anemia which may also require drug treatments.

The benefits of medicine use during pregnancy are not restricted to the recovery of maternal health but also result in some advantages for the fetus as well, because the maternal well-being is important for the optimal development of the fetus. Poorly controlled diabetes mellitus, particularly type 1 is teratogenic. However, the appropriate management of diabetic pregnant women can prevent diabetic embryopathy [46]. In addition the effective treatment of infectious diseases of genital organs can significantly reduce the prevalence of preterm birth and its related effects, among others, undescended testis [47]. Finally the periconceptional folic acid or folic acidcontaining multivitamin supplementation can prevent most neural-tube defects [48] and a considerable number of CAs in the cardiovascular system, urinary tract and limb deficiencies [49-51].

Previously we mentioned that less than $1 \%$ of CAs may be caused by human teratogenic drugs. The number of CAs induced by human teratogenic drugs is about 6 per 1,000 on the basis of Table 1 and 2 (Table 3). Of course, we have to do our best to limit this risk. However, there is another aspect of CA prevention which is connected with drug use. High fever (at least $38.9^{\circ} \mathrm{C}$ ) due to influenza [38] and acute respiratory diseases [39] during the second and third months of gestation occurs in about $4 \%$ of pregnant women in Hungary. Offspring of these pregnant women have a higher risk for neural-tube defects, cleft lip with or without cleft palate, posterior cleft palate and some other CAs. The total number of CAs which may be associated with hyperthermia is 8.7 per 1,000 and these CAs can be prevented by effective antifever therapy, including drugs (Table 3). Thus our estimation shows that CA-preventive effect of only antifever drugs may exceed the CA risk caused by all human teratogenic drugs.

Thus, a better balance is needed between the risk and benefit of drug treatments during pregnancy.

\section{General conclusions}

1. The use of teratogenic drugs should be avoided during pregnancy in less severe (non life-threatening) diseases such as acne and psoriasis. 
2. It is necessary to select non-teratogenic drugs instead of teratogenic drugs during pregnancy if possible and not harmful for pregnant women. The best example for this strategy is to replace coumarin derivative with heparin in early pregnancy.

3. The necessary use of teratogenic drugs may have to be continued in severe maternal diseases such as epilepsy and cancer if the discontinuation of treatment causes worsening of the disease and pregnant women agree with it.

4. Teratogenic drugs cannot cause CAs if the exposure is in the first month of gestation and in general after the third month of pregnancy. However, the fetotoxic effect of some drugs should be considered in the second part of pregnancy.

5. Recent effective ultrasound scanning can detect major fetal defects about the 18th-20th week of gestation with a high degree of efficacy. Thus we have a chance to evaluate the risk after the inadvertent or necessary use of teratogenic drugs during pregnancy. If serious fetal defects are detected, the couple can then be given information to help them decide whether to terminate their pregnancy or not.

6 . The use of non-teratogenic drugs may prevent the teratogenic effect of maternal diseases such as diabetes mellitus, influenza, and other acute infectious diseases with high fever and this preventable part of CAs exceeds the proportion of CAs caused by teratogenic drugs.

7. The periconceptional folic acid-containing multivitamin supplementation can prevent the major proportion of neural-tube defects and a considerable portion of cardiovascular, urinary tract CAs and limb deficiencies. According to the estimation of the WHO expert committee about one-third of major CAs are preventable by this new primary preventive method. Folic acid alone will also significantly reduce the first occurrence and recurrence of neural-tube defects. [52]

\section{Conflict of interest}

None declared.

\section{References}

1. Jones KL, Smith DW, Ulleland CL et al. Pattern of malformations in offspring of chronic alcoholic mothers. Lancet 1973. 1: 1267-1267.

2. Abel EL. Fetal Alcohol Syndrome and Fetal Alcohol Effects. New York: Plenum Press. 1983.

3. Czeizel AE, Kodaj I, Lenz W. Smoking during pregnancy and congenital limb deficiency. Brit Med J 1994. 308: 1473-1476.

4. Martinez-Friaz ML, Czeizel AE, Rodriquez-Pinilla E, Bermejo E. Smoking during pregnancy and Poland sequence: Results of a population-based registry and a case-control registry. Teratology 1999. 59: 35-38.

5. Hwang SJ, Beaty TH, Panny SR et al. Association study of transforming growth factor alpha (TGF-alpha) Tag1 polymorphism and oral clefts: indication of gene-environment interaction in a population-based sample of infants with birth defects. Am J Epidemiol 1995. 141: 629-636.

6. Harada Y. Congenital Minimata disease. In: Minimata Disease Study Group of Minimata Disease. Japan: Kumamoto University. 1968: 93117.

7. Czeizel AE. Drug exposure in pregnant women. Lupus 2004. 13: 740745 .

8. Lacroix I, Damase-Michel C, Lapeyre-Mestre M, Monastruc JL. Prescription of drugs during pregnancy in France. Lancet 2000. 42: 1735-1736.

9. Briggs GG, Freeman RK, Yaffe SJ. Drugs in Pregnancy and Lactation, $5^{\text {th }}$ ed. Baltimore: Wilkins and Wilkin, 1998.
10. Czeizel AE, Keller I, Bod M. An aetiological evaluation of increased occurrence of congenital limb reduction abnormalities in Hungary, 1975-1978. Int J Epid 1983. 12: 445-449.

11. Czeizel AE, Rockenbauer M, Siffel Cs, Varga E. Description and mission evaluation of the Hungarian Case-Control Surveillance of Congenital Abnormalities, 1980-1996. Teratology 2001. 63: 176-185.

12. Czeizel AE, Erös E, Rockenbauer M et al. Shortterm oral diazepam treatment during pregnancy. A population-based teratological casecontrol study. Clin Drug Invest 2003. 23: 451-462.

13. Czeizel AE, Rockenbauer M, Sorensen HT, Olsen J. A populationbased case-control study of oral chlordiazepoxide use during pregnancy and risk of congenital abnormalities. Neurotox Terat 2004. 26: 593-598.

14. Erős E, Czeizel AE,Rockenbauer M, et al. A population-based casecontrol teratologic study of nitrazepam, medazepam, tofisopam, alprazolum and clonazepam treatment during pregnancy. Eur J Obstet Gynec Reprod Biol 2002. 101: 147-154.

15. Czeizel AE. Lack of evidence of teratogenicity of benzodiazepine drugs in Hungary. Reprod Toxicol 1988. 1: 183-188.

16. Czeizel AE, Tomcsik M, Timár L. Teratologic evaluation of 178 infants born to mothers who attempted suicide by drugs during pregnancy. Obstet Gynec 1997. 90: 195-201.

17. Czeizel AE, Bod M, Halász P. Evaluation of anticonvulsant drugs during pregnancy in a population-based Hungarian study. Eur J Epid 1992. 8: 122-127.

18. Czeizel AE, Rockenbauer M. A population-based case-control teratological study of furosemide treatment during pregnancy. Clin Drug Invest 1999. 18: 307-315.

19. Czeizel AE, Rockenbauer M, Olsen J, Sorensen HT. A teratological study of aminoglycoside antibiotic treatment during pregnancy. Scand J Infect Dis 2000. 32: 309-313.

20. Czeizel AE, Kazy Z, Vargha P. Vaginal treatment with povidoneiodine suppositories during pregnancy. Int J Gynec Obstet 2004. 84: 83-85.

21. FASS (Swedish System of Approved Drugs). Classification of medical products for use during pregnancy and lactation: The Swedish System. Stockholm: Drug Information Ltd. 1993.

22. Australian Drug Evaluation Committee. Medicines in Pregnancy: An Australian Categorization of Risk. Canberra, Australia: AGPS. 1992.

23. Czeizel AE, Rockenbauer M. A population-based case-control study of oral oxytetracycline treatment during pregnancy. Eur J Obstet Gynec Reprod Biol 2000. 88: 27-33.

24. Czeizel AE, Rockenbauer M. Teratogenic study of doxycycline. Obstet Gynec 1997. 89: 524-528.

25. Czeizel AE, Rockenbauer M. Prevention of congenital abnormalities by vitamin A. Internat J Vit Nutr 1998. 68: 219-231.

26. Mastroiacovo P, Mazzone T, Addis A, et al. High vitamin A intake in early pregnancy and major malformations: A multicenter prospective controlled study. Teratology 1999. 59: 7-11.

27. Czeizel AE. The first trimester concept is outdated (Editorial). Congen Anom 2001. 41: 204.

28. Czeizel AE, Telegdi L, Tusnady G. Multiple Congenital Abnormalities. Budapest: Akadémiai Kiadó. 1988.

29. Czeizel AE. Prevention of oral clefts through the use of folic acid and multivitamin supplements: evidence and gaps. In: Wyszinski DF, ed. Cleft Lip and Palate: From Origin to Treatment. New York: Oxford University Press. 2002: 443-457.

30. Czeizel AE, Puho E, Sorensen HT, Olsen J. Possible association between different congenital abnormalities and use of different sulfonamides during pregnancy. Congen Anom 2004. 44: 79-86.

31. Czeizel AE, Rockenbauer M. A population-based case-control teratologic study of oral metronidazole treatment during pregnancy. Brit J Obstet Gynec 1998. 105: 322-327.

32. Czeizel AE, Kazy Z, Puho E. A population-based case-control teratologic study of topical miconazole. Congen Anom 2004. 44: 4145.

33. Kazy Z, Puho E, Czeizel AE. The possible association between the combination of vaginal metronidazole and miconazole treatment and poly-syndactyly. Population-based case-control teratologic study. Reprod Toxic. 2005. 20: 89-94. 
34. Czeizel AE, Puho E, Bánhidy F, Ács N. Oral pyridoxine during pregnancy. Potential protective effect for cardiovascular malformations. Clin Drug Invest 2004. 5: 259-269.

35. Rockenbauer M, Czeizel AE, Olsen J, et al. Recall bias in a casecontrol surveillance system on the use of medicine during pregnancy. Epidemiology 2001. 12: 461-466.

36. Czeizel AE, Petik D, Vargha P. Validation studies of drug exposures in pregnant women. Pharmacoepid Drug Safety 2003. 12: 409-416.

37. de Vries Cs, de Valle HEK, Cornel MC, de Jong-van den Berg. Registration of drug use in a birth defect monitoring system: a priority worthy of emphasis. Int J Risk Safety in Medicine 1993. 4: 2734.

38. Acs N, Bánhidy F, Puho E, Czeizel AE. Population-based case-control study of influenza during pregnancy for congenital abnormalities. Birth Defects Research (Part A); submitted.

39. Acs N, Bánhidy F, Puho E, Czeizel AE. Population-based casecontrol study of acute infectious diseases of respiratory system for congenital abnormalities. Obstet Gynec; submitted.

40. Czeizel AE. Ten years of experience in periconceptional care. Eur J Obstet Gynec Reprod Biol 1999. 84: 43-49.

41. Acs N, Puho E, Bánhidy F, Czeizel AE. Association between bronchial asthma in pregnancy and shorter gestational age in a population-based study. J Mater Fetal Neonat Med; Submitted.

42. Vallance P. Drugs and the fetus. Brit Med J 1996. 312: 1053-1054.

43. Czeizel AE. Analysis of medical indications for induced abortions. Orvosi Hetilap 1983. 124: 1297-1302.
44. Czeizel AE, Métneki J. Evaluation of counselling for pregnant women exposed to potentially hazardous environmental factors. Acta Paediat Hung 1985. 26: 175-186.

45. Czeizel AE, Intődy $\mathrm{Z}$, Modell $\mathrm{B}$. What proportion of congenital abnormalities can be prevented? Brit Med J 1993. 306: 499-503.

46. Nielsen GL, Norgaard B, Puho E, at al. Risk of specific congenital abnormalities in offspring of women with diabetes. Diabet Medicine 2005. 22: 693-696.

47. Czeizel AE, Toth $\mathrm{M}$, Rockenbauer $\mathrm{M}$. No teratogenic effect after clotrimazole therapy during pregnancy. Epidemiology 1999. 10: 437440.

48. Czeizel AE, Dudás I. Prevention of the first occurrence of neural-tube defects by periconceptional vitamin supplementation. N Engl J Med 1992. 327: 1832-1835.

49. Czeizel AE. Prevention of congenital abnormalities by periconceptional multivitamin supplementation. Brit J Med 1993. 306: 1645-1648.

50. Czeizel AE. Reduction of urinary tract and cardiovascular defects by periconceptional multivitamin supplementation. Am J Med Genet 1996. 62: 179-183.

51. Czeizel AE, Dobo M, Vargha P. Hungarian cohort-controlled trial of periconceptional multivitamin supplementation shows a reduction in certain congenital abnormalities. Birth Defects research (Part A) 2004.70: 853-861.

52. Taruscio D. Folic acid: from research to public health practice. In: Report of WHO Regional Office for Europe and the Instituto Superiore di Sanita; November 11-12, 2002; Rome.

\section{Tables}

Table 1. Drugs with high and moderate teratogenic risk, their FDA categories and cardinal congenital abnormalities (CAs) and the number of their use in the mothers of cases with CA and controls without CAs in the HCCSCA, 1980-2002

\begin{tabular}{|c|c|c|c|c|c|}
\hline $\begin{array}{l}\text { Chemical substance } \\
\text { (generic name) }\end{array}$ & Trade names & $\begin{array}{l}\text { FDA risk } \\
\text { categories } \\
(\%)\end{array}$ & CAs & $\begin{array}{c}\text { Cases } \\
(\mathrm{N}=29,922)\end{array}$ & $\begin{array}{l}\text { Controls } \\
(\mathrm{N}=52,299)\end{array}$ \\
\hline \multicolumn{6}{|l|}{ High risk (more than $25 \%$ ) } \\
\hline Thalidomide & Contergan & 75 & $\begin{array}{l}\text { Phocomelia, } \\
\text { CAs of external ear, } \\
\text { Facial hemangioma }\end{array}$ & 0 & 0 \\
\hline Androgenic hormones & & 40 & Masculinized exter-nal genitalia in girls & & \\
\hline Danazol & Danoval & $\mathrm{X}$ & & 0 & 0 \\
\hline Methyltestorenone & Ambosex & $\mathrm{X}$ & & 2 & 0 \\
\hline Nandrolone & Nerobolil & $X$ & & 6 & 10 \\
\hline \multicolumn{6}{|l|}{ Moderate risk (10-25\%) } \\
\hline Isotretinoin & Accutane & $\mathrm{X}$ & Microtia & 1 & 1 \\
\hline & Roaccutan & & Cardiac CAs & & \\
\hline \multirow[t]{2}{*}{ Etretinate } & Tigason & $\mathrm{X}$ & Small ear & 0 & 0 \\
\hline & Neotigason & & Adactyly Cardiac CAs & & \\
\hline Coumarin derivative & $\begin{array}{l}\text { Warfarin, } \\
\text { Dicumarol, } \\
\text { Syncumar }\end{array}$ & $\mathrm{D}$ & $\begin{array}{c}\text { Nasal hypoplasia-depressed nasal } \\
\text { bridge }\end{array}$ & 6 & 8 \\
\hline Oxytetracycline & $\begin{array}{l}\text { Tetramycin, } \\
\text { Tetran, } \\
\text { Chlomocycline }\end{array}$ & $\mathrm{D}$ & Staining of deci-duous teeth & 206 & 199 \\
\hline D-penicillamine & $\begin{array}{l}\text { Duprenil, } \\
\text { Byanodine }\end{array}$ & $\mathrm{D}$ & Cutis laxa & 2 & 3 \\
\hline Diethylstilbestrol & $\begin{array}{l}\text { Stilbestrol, } \\
\text { Syntestrin }\end{array}$ & $X$ & Clitoromegaly, Hypotrophic testis & 11 & 8 \\
\hline Total No. & & & & 234 & 229 \\
\hline$\%$ & & & & 0.8 & 0.4 \\
\hline
\end{tabular}

*not approved in USA, therefore thalidomide was not classified

Table 2. Drugs with low (less than 10\%) and very low (less than $3 \%$ ) teratogenic risk used in Hungary and the number of cases and controls in the HCSCA,1980-2002

\begin{tabular}{|c|c|c|c|c|}
\hline Chemical substances (generic name) & Trade names & FDA category & Cases (N=29922) & $\begin{array}{c}\text { Controls } \\
\text { (N=52599) }\end{array}$ \\
\hline & & & & \\
\hline & Antineoplastic drugs & & 2 \\
\hline Azathioprine & Imuran & $\mathrm{D}$ & 2 & 0 \\
\hline Cyclophosphamide & Cytoxan & $\mathrm{D}$ & 2 & 1 \\
\hline Chlorambucil & Leukeran & $\mathrm{D}$ & 0 & 1 \\
\hline Mannomustine & Degranol & $\mathrm{D}$ & 0 & 1 \\
\hline Melphalan & Alkeran & $\mathrm{D}$ & 0 & 0 \\
\hline Mercaptopurine & Leupurin & $\mathrm{D}$ & 0 & 19 \\
\hline Methotrexate & Methotrexat & $\mathrm{D}$ & 1 & 2 \\
\hline Mitobronitol & Myelobromol & $\mathrm{D}$ & 6 & 0 \\
\hline Ritrosulfane & Lycurim & $\mathrm{D}$ & 0 & 31 \\
\hline Vincristine & Vincristin & $\mathrm{D}$ & 2 & 13 \\
\hline Subtotal & & & & \\
\hline
\end{tabular}




\begin{tabular}{|c|c|c|c|c|}
\hline \multicolumn{5}{|c|}{ Anticonvulsant drugs } \\
\hline Clonazepam & Antelepsin & $\mathrm{C}$ & 6 & 5 \\
\hline & Clonazepamum & & & \\
\hline & Rivotril & & & \\
\hline \multirow[t]{6}{*}{ Carbamazepine } & Azepal & B & 47 & 41 \\
\hline & Neurotop & & & \\
\hline & Stazepine & & & \\
\hline & Tegretol & & & \\
\hline & Temporal & & & \\
\hline & Timonl & & & \\
\hline Ethosuximide & Suxilep & C & 4 & 3 \\
\hline Lamotrigine & Lamictal & $\mathrm{C}$ & 10 & 1 \\
\hline Mephenytoin & Sacerno & C & 8 & 5 \\
\hline Morsuximide & Perlepsin & * & 4 & 4 \\
\hline Oxcarbazepine & Trileptal & $\mathrm{D}$ & 1 & 0 \\
\hline Phenacemide & Neophedan & * & 3 & 2 \\
\hline \multirow[t]{2}{*}{ Phenytoin } & Epanutin & $\mathrm{D}$ & 35 & 39 \\
\hline & Diphedan & & & \\
\hline \multirow[t]{2}{*}{ Primidone } & Mysoline & $\mathrm{D}$ & 25 & 13 \\
\hline & Sertan & & & \\
\hline Sultiame & Ospolot & $\mathrm{D}$ & 12 & 2 \\
\hline Trimethadione & Ptimal & $\mathrm{D}$ & 4 & 1 \\
\hline \multirow[t]{4}{*}{ Valproic acid } & Convulex & $\mathrm{D}$ & 41 & 15 \\
\hline & Depakine & & & \\
\hline & Everiden & & & \\
\hline & Orfiril & & & \\
\hline \multirow[t]{2}{*}{ Subtotal } & & & 200 & 131 \\
\hline & Others & & & \\
\hline \multirow[t]{4}{*}{ Ergotamine } & Ergam & $\mathrm{D}$ & 37 & 64 \\
\hline & Kefalgin & & & \\
\hline & Neo-Gynofort & & & \\
\hline & Secadol & & & \\
\hline \multirow[t]{6}{*}{ Oestrogens very high dose } & Akrofollin & $\mathrm{D}$ & $20(40)$ & $8(43)$ \\
\hline & Hogival & & & \\
\hline & Limovan & & & \\
\hline & Limovanil & & & \\
\hline & Ovestin & & & \\
\hline & Strytanon & & & \\
\hline Methimazole (thiamazole) & Metothyrin & $\mathrm{D}$ & 10 & 1 \\
\hline Misoprostol & Cytotex & $X$ & 0 & 1 \\
\hline Lithium & Litium karbonat & $\mathrm{D}$ & 10 & 16 \\
\hline \multirow[t]{3}{*}{ Quinine } & Chinidinum & $\mathrm{D}$ & 40 & 85 \\
\hline & Chinacisal & & & \\
\hline & Diapulmon & & & \\
\hline Retinol very large dose & Vitamin A & $\mathrm{A}(\mathrm{X})$ & $0(39)$ & $4(95)$ \\
\hline Total No. & & & 340 & 341 \\
\hline$\%$ & & & 1.1 & 0.6 \\
\hline
\end{tabular}

*not approved in USA, therefore was not classified

Table 3. Comparative analysis of CAs induced by human teratogenic drugs and maternal hyperthermia due to influenza and acute infectious diseases of respiratory system

\begin{tabular}{|c|c|c|c|c|}
\hline \multicolumn{2}{|c|}{ Human teratogenic drugs } & & \multicolumn{2}{|c|}{$\begin{array}{l}\text { Maternal hyperthernia due to influenza and } \\
\text { acute infectious respiratory diseases }\end{array}$} \\
\hline Cases & Controls & & Cases & Controls \\
\hline & & Entire pregnancy & & \\
\hline $1.9 \%$ & $1.1 \%$ & & $14.5 \%$ & $13.4 \%$ \\
\hline \multicolumn{2}{|c|}{ OR with $95 \%$ CI } & & \multicolumn{2}{|c|}{ OR with $95 \%$ CI } \\
\hline \multicolumn{2}{|c|}{$1.79(1.59-2.01)$} & Second and third months & \multicolumn{2}{|c|}{$1.09(1.04-1.15)$} \\
\hline $1.4 \%$ & $0.8 \%$ & & $4.5 \%$ & $3.7 \%$ \\
\hline \multirow{2}{*}{\multicolumn{2}{|c|}{$\begin{array}{l}\text { OR with } 95 \% \text { CI } \\
1.74(1.52-2.00)\end{array}$}} & \multirow{3}{*}{$\begin{array}{l}\text { No. of CAs per } 1000 \text { informative offspring } \\
\text { due to teratogenic factors under study }\end{array}$} & \multicolumn{2}{|c|}{ OR with $95 \%$ CI } \\
\hline \multirow{2}{*}{\multicolumn{2}{|c|}{$\frac{1.74(1.52-2.00)}{6.0(4.2-8.0)}$}} & & \multicolumn{2}{|c|}{$1.25(1.15-1.36)$} \\
\hline & & & \multicolumn{2}{|c|}{$8.7(5.3-12.5)$} \\
\hline
\end{tabular}

